\title{
HOW LONG IS LONG ENOUGH: PUBLIC CONCERN ABOUT THE ACADEMIC CAREERS OF STUDENTS FROM AREAS DEVASTATED BY THE WENCHUAN EARTHQUAKE
}

\author{
Shu LI ${ }^{1)}$, Zuo-Jun WANG ${ }^{1,2)}$, Li-Lin RAO ${ }^{1)}$, Rui ZHENG ${ }^{1)}$, Xiao-Peng REN ${ }^{1)}$, \\ Jin-Zhen LI ${ }^{1), 3)}$, Huan LIU ${ }^{1,4)}$, Yan-Ling BI ${ }^{1,5)}$, Fei WANG ${ }^{1), 6}$, and Xin-Wen BAI ${ }^{1)}$ \\ ${ }^{1)}$ Institute of Psychology, Chinese Academy of Sciences, China, ${ }^{2)}$ Ningbo University, China \\ ${ }^{3)}$ Beijing Normal University, China, ${ }^{4)}$ Nanchang University, China \\ ${ }^{5)}$ Shaanxi Normal University, China, ${ }^{6)}$ Xiamen University, China
}

\begin{abstract}
To examine how the Wenchuan earthquake influenced public concern about the academic careers of students from earthquake-affected areas, we conducted three rounds of a survey at 1,6 , and 11 months after the disaster in devastated and nondevastated areas. We asked residents to estimate how many high school students out of 100 in the areas devastated by the Wenchuan earthquake would be admitted to college in the next year. The results indicated that the longer time from the disaster, the more concerned the public (both inside and outside the devastated areas) was about the students' academic careers. We dubbed this finding a "Psychological Typhoon Eye" effect. The underlying mechanisms and implications are discussed.
\end{abstract}

Key words: Wenchuan earthquake, psychological immunization, adapting, cognitive dissonance

The Wenchuan earthquake, measuring 8.0 on the Richter scale, occurred on May 12, 2008, in the Sichuan Province of Southwest China. The death toll from the earthquake was 69,227, with 374,643 people injured, 17,923 listed as missing, and 4.8 million left homeless (official figures as of September 25, 2008, retrieved from http:// www.scio.gov.cn/gzdt/ldhd/200809/t222722.htm). When the earthquake struck, a disproportionate number of school buildings collapsed. In some places, schools were the only buildings that tumbled. More than 10,000 school buildings in Sichuan were badly damaged, almost 7,000 schools were completely destroyed, and many others suffered partial damage (retrieved June 5, 2008, from http://www.xprn.com/pr/08/06/083573111.html). Official figures state that more than 5,300 students have been confirmed dead or missing in the whole province (retrieved May 7, 2009, from http://english.sc.gov.cn/news/ 200905/t20090508_723574.shtml).

The Wenchuan earthquake occurred approximately one month before the national college entrance exam. After the disaster, the national college entrance exam, which

The writing up of this paper was partially supported by the Knowledge Innovation Project of the Chinese Academy of Sciences (No. KSCX2-YW-R-130) and the National Natural Science Foundation of China (No. 70871110). The authors would also like to thank the anonymous referee for helpful suggestions.

Correspondence concerning this article should be addressed to Dr. Xin-Wen Bai, Key Laboratory of Behavioral Science, Institute of Psychology, Chinese Academy of Sciences, 4A Datun Road, Chaoyang District, Beijing (100101), P. R. China (e-mail: baixw@psych.ac.cn). 




Fig. 1. High school students study in temporary tents in the devastated area. Note: This photo was taken by Dr. Yuan Zhou on May 30, 2008.

would normally have been held from June 7 to 9, was postponed to allow for relief and reconstruction work in the quake-hit regions. Most high school students in the affected area tried to continue their schooling in temporary shelters and tents (see Fig. 1). Being admitted to college is considered the most important turning point in one's life in China. Thus, it is not surprising that the public showed much concern about the academic careers of students from earthquake-devastated areas.

The psychological sequelae associated with natural disasters, such as an earthquake, have been extensively discussed in the psychological literature. Posttraumatic stress disorder (PTSD) and generalized anxiety are the most frequently reported post-trauma sequelae (Freedy, Shaw, Jarrell, \& Masters, 1992; Gibbs, 1989; Horowitz, 1977; Najarian, Goenjian, \& Pelcovitz, 2001; Pynoos et al., 1993; Rubonis \& Bickman, 1991; Scott, Knoth, Beltran-Quiones, \& Gomez, 2003). The psychopathological effect of the 2008 Wenchuan earthquake on survivors has also been investigated recently (e.g., Wang et al., 2009). However, little is known about whether residents inside and outside of the devastated areas have different levels of concerns about the impact of the disaster. There is some indication that residents outside of the devastated areas might have been overly concerned about the impact of the disaster. It was reported that blood banks in other parts of the country received so many donations in the first few days after the earthquake that the banks had to turn people away (accessed May 16, 2008, at http://news.xinhuanet.com/ english/2008-05/16/content_8188629.htm.), which turned out to be the first example of "overestimation of aid needed." Interestingly, Guedeney and Mendel (1973) found that, in a local survey of attitudes toward a nuclear power station in France, anxiety was lower among those living near the nuclear reactor than among those living further away. Maderthaner, Guttman, Swaton, and Otway (1978) also reported that respondents living 
nearest to a nuclear power plant reported little concern about possible hazards, and that concern increased at some further distance from the facility.

The present study aimed to assess whether concerns about the impact of the earthquake varied according to distance from the center of the disaster area. We focused on potential differences in the level of concern of residents in devastated versus nondevastated areas about the academic careers of students from the devastated areas.

To examine the concerns of residents inside and outside of the devastated areas, we conducted three rounds of a survey at 1, 6, and 11 months after the disaster. We asked participants to estimate how many high school students out of 100 in earthquakedevastated areas would be admitted to colleges in the next year. We considered a lower estimate indicative of greater concern about the students' academic careers, and vice versa.

\section{METHOD}

\section{Participants}

A convenience sample of residents in Tangshan $(N=1,175)$ and twelve administrational areas in the Sichuan province $(N=4,986)$ was surveyed 1,6 , and 11 months after the Wenchuan earthquake. Inclusion criteria included an age of at least 18 years, literacy, and a willingness to provide personal contact information (for demographic characteristics of participants, see Table 1).

We deliberately selected Tangshan in the Hebei province to represent a non-devastated area. Considering that Tangshan was completely unaffected by the 2008 Wenchuan earthquake but suffered damage three decades ago from the 20th century's largest earthquake (Tangshan earthquake), which killed at least 240,000 people, we anticipated that residents of Tangshan would be an ideal control group in this study; we cannot envision a more suitable sample of residents who are able to put themselves in the position of the Wenchuan earthquake victims.

\section{Materials and procedure}

The question of how many high school students out of 100 in devastated areas would be admitted to colleges in the next year was interspersed among other content questions in a questionnaire that was distributed to residents in both devastated and non-devastated areas. Given that most of the participants we surveyed were not highly educated and that, as humans have evolved, the "natural" information format has been frequencies rather than probabilities or percentages (Cosmides \& Tooby, 1996; Gigerenzer \& Hoffrage, 1995), we asked the participants to estimate the frequency of high school students (out of 100) from devastated areas who would be admitted to colleges in the next year, instead of directly asking them to estimate the admission rate of the college entrance examination. Respondents were paid a small fee (or were given a small present, such as soap, a towel, and washing powder) for each completed questionnaire.

\section{RESULTS}

A two-way ANOVA was employed, with the estimated number of students from areas devastated by the Wenchuan earthquake who would be admitted to college as the dependent variable, and location (devastated area, i.e., Sichuan, and non-devastated area, i.e., Tangshan) and the survey round as the independent factors.

Interestingly, the analysis revealed that the mean estimated number of high school students from areas affected by the Wenchuan earthquake who would be admitted to 
Table 1. Demographic Characteristics of Residents in Tangshan and Sichuan

\begin{tabular}{|c|c|c|c|}
\hline Characteristic & $\begin{array}{l}\text { Participants in Tangshan } \\
\qquad(N=1,175)\end{array}$ & $\begin{array}{l}\text { Participants in Sichuan } \\
\qquad(N=4,986)\end{array}$ & Total $(N=6,161)$ \\
\hline \multicolumn{4}{|l|}{ Age (years) } \\
\hline Mean & $39.87 \pm 12.09$ & $32.21 \pm 9.21$ & $33.68 \pm 10.28$ \\
\hline \multirow[t]{2}{*}{ Median } & 39 & 32 & 33 \\
\hline & \multicolumn{3}{|c|}{ No. of Participants (\%) } \\
\hline \multicolumn{4}{|l|}{ Round } \\
\hline First & $382(32.5)$ & $1,379(27.6)$ & $1,761(28.6)$ \\
\hline Second & $399(34.0)$ & $1,789(35.9)$ & $2,188(35.5)$ \\
\hline Third & $394(33.5)$ & $1,818(36.5)$ & $2,212(35.9)$ \\
\hline \multicolumn{4}{|l|}{ Sex } \\
\hline Male & $489(41.6)$ & $1,316(26.4)$ & $1,805(29.3)$ \\
\hline Female & $683(58.1)$ & $3,616(72.5)$ & 4,299 (69.8) \\
\hline Unknown & $3(0.3)$ & $54(1.1)$ & $57(0.9)$ \\
\hline \multicolumn{4}{|l|}{ Education } \\
\hline Below college degree & $696(59.2)$ & $4,019(80.6)$ & $4,715(76.5)$ \\
\hline College degree or above & $472(40.2)$ & $893(17.9)$ & $1,365(22.2)$ \\
\hline Unknown & $7(0.6)$ & $74(1.5)$ & $81(1.3)$ \\
\hline \multicolumn{4}{|l|}{ Occupation } \\
\hline Civil servant & $35(3.0)$ & $28(0.6)$ & $63(1.0)$ \\
\hline Employee of public institutions & $213(18.1)$ & $255(5.1)$ & $468(7.6)$ \\
\hline Business employee & $529(45.0)$ & $2457(49.3)$ & $2986(48.5)$ \\
\hline Medical worker & $71(6.0)$ & $21(0.4)$ & $92(1.5)$ \\
\hline Teacher & $85(7.2)$ & $64(1.3)$ & $149(2.4)$ \\
\hline Farmer & $14(1.2)$ & $553(11.1)$ & $567(9.2)$ \\
\hline Student & $16(1.4)$ & $122(2.4)$ & $138(2.2)$ \\
\hline Other & $201(17.1)$ & $1226(24.6)$ & $1427(23.2)$ \\
\hline Unknown & $11(0.9)$ & $258(5.2)$ & $269(4.4)$ \\
\hline
\end{tabular}

college in the next year was lower for participants in Tangshan $(M=53.24, S D=27.99$, $F(1,6155)=15.99, p<0.001)$ than for those in Sichuan $(M=56.59, S D=29.25)$. This result suggested that participants outside of the devastated areas were more concerned about the academic careers of students from affected areas than were the participants in the devastated areas.

The main effect of survey round was also significant $\left(F_{(2,6155)}=17.96, p<0.001\right)$. 


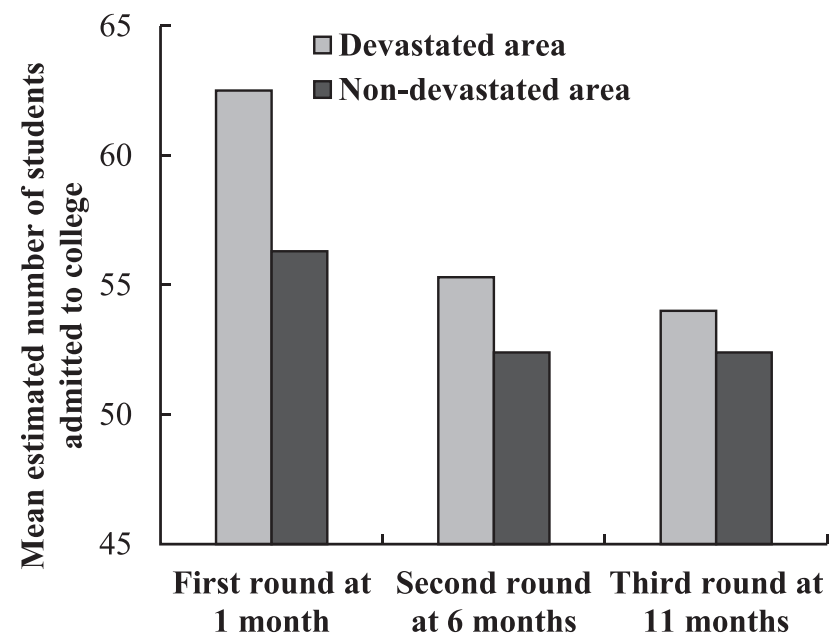

Fig. 2. Mean estimated number of high school students out of 100 from areas affected by the Wenchuan earthquake who would be admitted to college in the next year as a function of location (Sichuan and Tangshan) and rounds of the survey (at 1, 6, and 11 months after the disaster).

Further post hoc analysis showed that the mean estimated number of students who would be admitted to college was significantly higher in the first round of the survey $(M=60.83$, $S D=28.29)$ than in the second $(M=54.63, S D=28.64)$ and third rounds $(M=53.36$, $S D=29.56, p<0.001)$, and the difference between the second and third rounds was not statistically significant $(p=0.14)$. No interaction between the devastated area and the round of surveys was found $\left(F_{(2,6155)}=1.60, p>0.10\right.$, see Fig. 2$)$. These results indicated that the longer the time since the disaster, the more concerned the participants were about the academic careers of students from earthquake-affected areas.

It is worth noting that the actual admission rate following the college entrance examination in Sichuan in 2008 was about 60\% (Wang, 2009). The mean estimated admission rate was 56.29 and 53.24 for participants of devastated and non-devastated areas, respectively, which indicated that all participants, and those from unaffected areas in particular, were overly concerned about the students' academic careers. On the other hand, the mean estimated admission rate was $60.83,54.63$, and 53.36 at 1,6 , and 11 months after the disaster, respectively, indicating that, as time elapsed, the public became more "irrationally" worried about the students' academic careers.

"Typhoon eye" is a meteorological term that refers to a zone of weak winds existing in the center of the swirling vortex of a hurricane or typhoon. We dubbed our findings the "Psychological Typhoon Eye" effect: residents outside of the devastated areas were more concerned about the students' academic careers than were those inside the devastated areas, and, the longer time since the disaster, the more worry and fear a resident inside or outside of the devastated areas felt. 


\section{GENERAL DISCUSSION}

We examined how the Wenchuan earthquake influenced concerns about the academic careers of students from areas devastated by the earthquake. A so-called "Psychological Typhoon Eye" effect was found: residents outside of the devastated areas were more concerned about the students' academic careers than were those inside the devastated areas, and, with time, such concerns increased.

These results were somewhat in accord with the studies that indicated that patients who are experiencing some adverse condition (handicap or illness) assign it a higher utility (that is, closer to normal health) than those who are simply imagining the condition (Boyd, Sutherland, Heasman, \& Tritchler, 1990; Gabriel et al., 1999). Similarly, our results revealed that the participants who directly experienced the Wenchuan earthquake were less concerned than those not impacted by it.

The "psychological immunization" theory (Henderson, Montgomery, \& Williams, 1972), which was used to explain the effect of distance upon risk perception (Maderthaner et al., 1978), seems insufficient to account for the present results. The "psychological immunization" theory assumes that resistance to adverse life events is naturally acquired through repeated exposure. However, our results showed that public worry increased over time.

Our findings appear to agree with the theory of cognitive dissonance (Festinger, 1957), which assumes that cognitive dissonance is an uncomfortable psychological state in which an individual experiences two incompatible beliefs or cognitions. An individual is motivated by the attendant discomfort to act in such a manner as to reduce dissonance. The residents who were directly impacted by the Wenchuan earthquake were more eager and more motivated to believe that the disaster had little influence upon students' academic careers than were those far from the affected area.

Understanding and predicting public response to disasters would be helpful for risk analysis and policy-making. The "Psychological Typhoon Eye" effect highlights the importance of long-term psychological intervention after the earthquake for residents in both devastated and non-devastated areas. It should be acknowledged that, in our studies, we have not yet identified the underlying mechanism of the "Psychological Typhoon Eye" effect, and it is worth future investigation.

\section{REFERENCES}

Boyd, N., Sutherland, H., Heasman, K., \& Tritchler. 1990. Whose utilities for decision analysis? Medical Decision Making, 10, 1058-1067.

Cosmides, L., \& Tooby, J. 1996. Are humans good intuitive statisticians after all? Rethinking some conclusions from the literature on judgment under uncertainty. Cognition, 58, 1-73.

Festinger, L. 1957. A Theory of Cognitive Dissonance. California: Stanford University Press.

Freedy, J. R., Shaw, D. L., Jarrell, M. P., \& Masters, C. R. 1992. Towards an understanding of the psychological impact of natural disasters: An application of the conservation resources stress model. Journal of Traumatic Stress, 3, 441-454.

Gabriel, S. E., Kneeland, M. P. H., Melton, L. J., Moncur, M., Ettinger, B., Tosteson, A., et al. 1999. Health- 
related quality of life in economic evaluations for osteoporosis: Whose values should we use? Medical Decision Making, 19, 141-148.

Gibbs, M. S. 1989. Factors in the victims that mediate between disaster and psychopathology: A review. Journal of Traumatic Stress, 2, 489-514.

Gigerenzer, G., \& Hoffrage, U. 1995. How to improve Bayesian reasoning without instruction: Frequency format. Psychological Review, 102, 684-704.

Guedeney, C., \& Mendel, G. 1973. L'angoisse atomique et les centrales nucléaires: Contribution psychanalytique et sociopsychanalytique à l'étude d'un phénomène collectif. Paris: Payot.

Henderson, A. S., Montgomery, I. M., \& Williams, C. L. 1972. Psychological immunisation: A proposal for preventive psychiatry. Lancet, 20, 1111-1112.

Horowitz, M. 1977. Stress response syndromes and brief psychotherapy. Philadelphia: Pennsylvania Hospital.

Maderthaner, R., Guttman, G., Swaton, E., \& Otway, H. J. 1978. Effect of distance upon risk perception. Journal of Applied Psychology, 63, 380-382.

Najarian, L. M., Goenjian, A. K., \& Pelcovitz, D. 2001. The effect of relocation after a natural disaster. Journal of Traumatic Stress, 14, 551-526.

Pynoos, R., Goenjian, A. K., Tashjian, M., Karakashian, M., Manjikian, M., Manoukian, G., Steinberg, A. M., \& Fairbanks, L. A. 1993. Post-traumatic stress reactions in children after the 1988 Armenian earthquake. British Journal of Psychiatry, 163, 239-247.

Rubonis, A. V., \& Bickman, L. 1991. Psychological impairment in the wake of disaster: The disasterpsychopathology relationship. Psychological Bulletin, 109, 384-399.

Scott, R. L., Knoth, R. L., Beltran-Quiones, M., \& Gomez, N. 2003. Assessment of psychological functioning in adolescent earthquake victims in Colombia using the MMPI-A. Journal of Traumatic Stress, 16, 49-57.

Wang, L. (2009, June 16). A total of 1528 colleges and universities plan to recruit students in Sichuan Province: 6 out of 10 students would have the chance to go to colleges. Retrieved from http:// scnews.newssc.org/system/2009/06/16/012034001.shtml.

Wang, L., Zhang, Y., Wang, W., Shi, Z., Shen, J., Li, M., et al. 2009. Symptoms of posttraumatic stress disorder among adult survivors three months after the Sichuan earthquake in China. Journal of Traumatic Stress, 22, 444-450. 